Revista PSICOLOGIA, 2014, Vol. 28 (2), 63-70

\title{
Os efeitos (in)visibilizadores do cárcere: as contradições do sistema prisional
}

\author{
Mariana Barcinski ${ }^{1}$, Sabrina Daiana Cúnico ${ }^{1}$ \\ ${ }^{1}$ Pontifícia Universidade Católica do Rio Grande do Sul (PUCRS)- Brasil
}

\begin{abstract}
Resumo: A prisão é historicamente reconhecida por produzir a uniformização dos indivíduos submetidos às suas normas, bem como o apagamento das identidades pessoais. Às tentativas institucionais de invisibilização - expressas através do controle constante dos comportamentos - correspondem estratégias pessoais de afirmação das singularidades e de diferenciação. Considerando as dinâmicas invisibilizadoras da prisão, o objetivo deste trabalho é discutir a aparente contradição envolvida no reconhecimento da possibilidade de a prisão - entendida como um instrumento de segregação social - se constituir em um espaço de visibilidade para homens e mulheres encarcerados. Tal contradição é discutida a partir do contexto social e econômico da população usualmente encarcerada no Brasil, alijada historicamente de direitos sociais básicos. É neste contexto mais amplo de marginalização, portanto, que a prisão pode potencialmente visibilizar subjetividades socialmente marginalizadas.
\end{abstract}

Palavras-chave: Prisão; Visibilidade; Contexto social; Gênero.

The (un)visible effects of prison: the contradictions of the prison system: Prison is historically recognized for uniformizing individuals submitted to its rules, as well as for erasing personal identities. To the institutional attempts to promote invisibility - expressed through constant behavior control correspond personal strategies of affirmations of uniqueness and differentiation. Considering the invisibilization promoted by prison, the aim of this paper is to discuss the apparent contradiction involved in recognizing the possibility for prison - understood as an instrument of social segregation - to constitute a space of visibility for both incarcerated men and women. This contradiction is discussed within the social and economic context of the population usually incarcerated in Brazil, historically excluded from the access to social rights. It is in this broader context of marginalization that prison can potentially make visible socially marginalized subjectivities.

Keywords: Prison; Visibility; Social Context; Gender.

Os sistemas punitivos atuais são reflexos de uma construção histórica, em que os castigos explícitos e públicos deram lugar a outras formas de punição, como o surgimento das prisões e a privação de liberdade como pena. 0 sistema prisional foi pensado como um mecanismo eficiente de adestramento social daqueles sujeitos que possuíam alguma conduta desviante, uma vez que seu objetivo era torná-los aptos a retornar ao convívio da sociedade após estarem devidamente ressocializados (Miyamoto \& Krohling, 2012). Assim, as punições por meio dos suplícios dos corpos foram gradativamente sendo substituídas por técnicas de vigilância através de formas de regulação social, as quais estipulariam as regras do comportamento disciplinado (Foucault, 1987).

A violência incorpórea representada pelas práticas disciplinadoras da instituição prisão atua no sentido de anular as vontades e os desejos pessoais (Fonseca, 2006). Segundo Michel Foucault (1987), ainda que através de métodos mais sutis de correção e controle, é sobre o corpo do apenado que a prisão exerce o seu poder, docilizando e submetendo este corpo à sujeição constante de suas forças. 0 castigo físico dos suplícios, portanto, dá lugar à suspensão dos direitos individuais e, em última instância, à suspensão da vida.

A partir de Erving Goffman (1996), a discussão a respeito da prisão pode ser situada no âmbito mais amplo das instituições totais. Nestas instituições, todas as atividades que dizem respeito à vida de uma pessoa são realizadas em conjunto, sob uma única autoridade. Assim, mesmo os menores segmentos das atividades do indivíduo estão sujeitos a regulamentos e julgamentos por parte daqueles que

Dados de contacto para correspondência: Mariana Barcinski, Programa de Pós-Graduação em Psicologia da Pontifícia Universidade Católica do Rio Grande do Sul. Av. Ipiranga 6681, Parternon. 90.619-900 Porto Alegre RS Brasil. E-mail: mariana.barcinski@pucrs.br. 
administram a instituição.

As instituições totais são reconhecidas por promoverem sistematicamente a "mortificação do eu" (Goffman, 1996, p. 24). A retirada dos bens pessoais na entrada, a separação do interno das relações que mantinha no mundo externo, a obrigatoriedade de realização de uma rotina diária que não leva em conta as suas vontades (mas sim a organização institucional), bem como a perda de espaços e de momentos de intimidade e privacidade são alguns dos aspectos que compõem a mutilação e degradação do eu em tais instituições, uma vez que promovem a uniformização dos indivíduos. 0 aprendizado da reverência para com os superiores integra este processo de destituição da identidade pessoal (Goffman, 1996).

As fronteiras estruturais da prisão demarcam um modelo de vida temporário e específico em que as relações lá estabelecidas possuem dinâmicas próprias (Cunha, 1994). Compreendendo o conceito de "prisionização" - introduzido por Donald Clemmer em 1940 - como sendo a apropriação por parte do indivíduo da cultura da prisão, isto é, dos seus costumes, valores e regras, Manuela Ivone Cunha (1991) reflete sobre os efeitos que as transformações ocorridas ao longo do processo de encarceramento têm na vida do sujeito. Para a autora, um destes efeitos é justamente o rompimento com os modelos externos e a resignação aos códigos internos da prisão. Tal resignação se daria como uma forma de adaptação ao modo de vida prisional e funcionaria como um "amortecedor do choque que ela ocasiona" (Cunha, 1991, p. 166).

Assim, a prisão se constitui como um espaço de múltiplas segregações. Evidentemente, a mais aparente é a que separa os encarcerados do restante da sociedade. No entanto, há outras menos perceptíveis, como a divisão dos presos dentro do próprio ambiente prisional, distribuindo-os em celas, galerias, solitária, bem como limitando ou autorizando o acesso dos presos aos demais espaços da prisão, tais como o refeitório, corredores, oficinas, etc. Esta divisão não só reflete as distinções entre quem está mais próximo ou mais distante das normas estabelecidas, como delineia os limites entre um maior ou menor grau de punição (Colares \& Chies, 2010).

Nesse contexto, as trocas com o ambiente externo - através de correspondências e visitas - ganham notoriedade, tornando-se um foco abrangente de regulamentação (Cunha, 1994). As visitas são restritas e os produtos levados à instituição prisional são limitados e verificados. Além disso, é obrigatório que todos os visitantes sejam revistados - em alguns casos de forma invasiva -, como nas revistas íntimas (Silva \& Guzzo, 2007).

Para além das normas institucionais previamente estabelecidas que compõem o regulamento da prisão, inúmeras outras são formuladas permanentemente de modo a responder a novas situações na vida prisional e estabelecer a restrição da autonomia individual das pessoas privadas de liberdade. Como exemplos podemos citar a interferência da instituição em relação às roupas dos apenados e a interdição arbitrária de objetos levados no momento de visitação (Cunha, 1994).

Ao tomarmos por base tais apontamentos, ressaltamos que o presente artigo está organizado através da análise de alguns pontos fundamentais que se intercomunicam, tais como: as características associadas à prisão e os movimentos de diferenciação das pessoas privadas de liberdade em meio às tentativas de uniformização que correspondem às instituições prisionais. Nesse sentido, o objetivo deste trabalho é fomentar a discussão a respeito da aparente contradição envolvida no reconhecimento da possibilidade de a prisão - entendida como um instrumento de segregação social - se constituir em um espaço de visibilidade para homens e mulheres encarcerados.

As motivações para o crime, os tipos de delitos cometidos e o impacto do encarceramento, bem como as formas de lidar com estes impactos são diferentes para homens e mulheres (Cerneka, 2009; Moe \& Ferraro, 2006). Desta forma, discutiremos a suposta contradição acima mencionada a partir do reconhecimento das especificidades do aprisionamento masculino e feminino. Trata-se, portanto, de entender a partir de uma perspectiva de gênero os distintos movimentos de resistência às tentativas uniformizadoras e os efeitos (in)visibilizadores do cárcere.

\section{AS MULHERES NAS INSTITUIÇõES PRISIONAIS: UMA QUESTÃO DE GÊNERO}

Os estudos tradicionais com perspectivas teóricas e socio-históricas da instituição prisional, tais como os de Michel Foucault (1987) e Erving Goffman (1996), retratam a experiência do cárcere a partir da vivência das prisões masculinas, ou seja, a partir de um ponto de vista masculino. Ao contrário do que acontece com a designação das "prisões femininas", não é comum o uso de "prisões masculinas" quando os internos são homens. Isto equivale a dizer que o gênero só é especificado quando se trata da análise de questões que têm por cenário uma prisão de mulheres (Cunha, 2007).

Elaine Pimentel (2013) pondera que o termo prisão, por si só, parece trazer implicitamente o adjetivo masculino. Assim, quando a palavra prisão é mencionada, ela parece se referir invariavelmente ao universo masculino. Para a autora, isto se dá em função de as prisões femininas serem tomadas como excepcionais, uma vez que os crimes cometidos por mulheres representam um número muito pequeno se 
comparados com os crimes em geral.

0 fato de a prisão em si ser masculina e masculinizante em grande parte de suas práticas torna as mulheres presas ainda mais invisíveis. Tal afirmação se reflete no improviso institucional que marca a situação da mulher no cárcere, a qual é tratada a partir de tentativas de adaptações do sistema já existente, refletindo o caráter androcêntrico do sistema prisional. No entanto, a assertiva de que a prisão se constitui em um espaço prioritariamente masculino deve ser compreendida para além dos dados que demonstram que o número de mulheres presas é muito inferior quando comparado aos homens. Ela ilustra o poder do corpo masculino, o qual mesmo em condições de confinamento possui mais capacidade de se deslocar, de circular no ambiente prisional, de interagir e, assim, de sentir-se menos aprisionado (Colares \& Chies, 2010).

O corpo feminino, por outro lado, é objeto de maiores interdições, sendo vedadas algumas formas de expressão da feminilidade como o uso de roupas curtas ou apertadas e o uso de maquiagem, especialmente nos presídios em que homens e mulheres dividem o espaço da prisão (Colares \& Chies, 2010). Nesse sentido, percebemos que é, sobretudo, no corpo e através dele que se estabelece o controle institucional às mulheres encarceradas. Controle este que atravessado por uma lógica que pressupõe a existência de uma imagem considerada apropriada para o gênero feminino, a qual incluiria elementos de recato, pudor e sobriedade (Cunha, 1996).

Em virtude do aprisionamento, as mulheres que são mães passam a ser consideradas pela sociedade de modo geral e por elas próprias como "maternalmente não-ortodoxas" (Brown \& Bloom, 2009, p. 314), uma vez que são vistas como violadoras tanto da lei quanto do comportamento prescrito ao gênero feminino. Culturalmente, a maternidade é entendida como central na identidade da mulher, não sendo diferente para as mães cumprindo pena de privação de liberdade. Diante disto, a instituição tende a reforçar a domesticidade, o desejo de ser uma boa mãe e a culpa pela não manutenção do contato com os filhos, por entender que aquelas que buscam manter este contato têm maiores chances de reabilitação (Shamai \& Kochal, 2008).

Os estereótipos associados à feminilidade também se mostram presentes ao analisarmos a divisão sexual do trabalho no ambiente prisional, sendo as oportunidades de trabalho para as mulheres encarceradas frequentemente delimitadas às aulas de culinária, artesanato, jardinagem ou costura, ou seja, atividades consideradas de "natureza feminina" (Miyamoto \& Krohling, 2012, p. 231). Situação semelhante ocorre com os tipos de punições impostas às mulheres que descumprem alguma regra institucional. Nas palavras de Leni Beatriz Correia Colares e Luiz Antônio Bogo Chies (2010): "a severidade da punição será tanto maior quanto mais o comportamento estiver afastado do padrão de docilidade, conformidade e dependência que devem caracterizar o feminino" (p. 419).

Ao discorrer sobre a forma diferenciada como o aprisionamento impacta homens e mulheres, Manuela Ivone Cunha (1994) afirma que a experiência da prisão é capaz de tornar estes últimos seres "não situáveis" (p. 193). Como ser primordialmente relacional, a mulher experimenta a separação e o abandono impostos pelo encarceramento como uma ameaça a sua própria identidade. Desta forma, a mulher encarcerada é duplamente sentenciada: pelo crime cometido e pela impossibilidade de desempenhar suas funções maternais e familiares (Cunha, 1994; Forsyth, 2003). Soma-se a estas questões o fato de a mulher privada de liberdade, frequentemente, receber menos visitas do que os homens, o que fomenta o sentimento de abandono e solidão vivenciado por elas (Carvalho, Valente, Assis \& Vasconcelos, 2006; Cerneka, 2009).

0 não exercício das funções de cuidado socialmente atribuídas às mulheres tem como uma das consequências a reedição de formas de relações afetivas e sexuais na prisão feminina. Mariana Barcinski (2012) aponta como frequentemente estas relações estão fundadas na heteronormatividade, reproduzindo no espaço prisional as normas de gênero da sociedade mais ampla. Portanto, as presas baseiam estas relações em uma divisão clara de papéis masculinos e femininos, respectivamente associados a comportamentos mais ativos e passivos. Além disto, relações filiais e maternais são também estabelecidas na prisão, nas quais as presas assumem os papéis de filhas e mães em suas relações intramuros. Ser capaz de estabelecer estes novos vínculos na prisão reafirma, de alguma forma, a habilidade feminina de cuidado e proteção daqueles em seu entorno, dando sentido renovado à identidade das detidas.

\section{A PRISÃo COMO CATALIZADORA DO PROCESSO DE INDIVIDUALIZAÇÃO}

Imersas em um ambiente que se caracteriza pela uniformização, a mortificação e o apagamento das singularidades, estudos têm demonstrado que as pessoas privadas de liberdade lançam mão de estratégias que lhes conferem certa visibilidade na instituição prisional. Adotadas de maneira mais ou menos deliberada, tais estratégias se constituem em mecanismos de resistência às dinâmicas normativas e patologizantes que caracterizam as instituições totais. 
Selmo Haroldo de Resende (2013, p. 362), a partir da análise de narrativas de homens presos, versa sobre o que chama de um "dialeto prisional", uma linguagem particular desenvolvida no ambiente da prisão. Nesta forma de linguagem, palavras que apresentam um significado original são dotadas de um sentido completamente diverso, configurando-se, segundo o autor, em uma forma de transgressão gramatical. Como exemplos, podemos citar a palavra "boi", que no ambiente prisional passa a ter o significado de "banheiro ou instalações sanitárias" e "madeira", que diz respeito à "propina", ou seja, quantia que um preso extorque do outro. É neste movimento de transgressão - ao se apropriarem e transformarem os significados originais das palavras - que o dialeto prisional não somente constitui o universo prisional, como também a própria subjetividade dos presos. Neste sentido, ao contestar a ordem discursiva vigente, a linguagem criada dentro dos muros da prisão reconhece e dá voz a um saber local específico, refletindo as dinâmicas e as relações estabelecidas no interior destas instituições.

Em pesquisa sobre os processos de subjetivação e resistência de um grupo de apenados em uma instituição prisional masculina do Rio Grande do Sul, no Brasil, Cristian Fabiano Guimarães, Stela Nazareth Meneghel e Carmen Silveira de Oliveira (2006) discutem acerca das estratégias por eles adotadas com o objetivo de diminuir o sofrimento e o estigma resultantes do encarceramento. Para os autores, qualquer reação à uniformização promovida pela prisão deve ser entendida como dispositivo de promoção de saúde mental, de afirmação das singularidades em face à normatização adoecedora produzida pelo cárcere. Em suas palavras “(...) entendemos saúde enquanto movimento de superação do aprisionamento em forças reativas, estratégia de resistência que arranca da existência a vida onde ela está aprisionada" (p. 635).

$\mathrm{Na}$ pesquisa acima referida, os autores observaram que alguns internos assinavam suas obras produzidas no cárcere, tais como poesias, desenhos e declarações, citando o artigo do código penal referente a seus crimes. Desta forma, os apenados estabeleciam relações hierárquicas entre eles, nas quais aqueles que cometiam crimes mais graves obtinham o respeito e o medo dos seus colegas supostamente menos perigosos. A afirmação, por parte dos internos, da sua periculosidade, configuravase em uma estratégia de resistência ao assujeitamento imposto pela prisão (Guimarães, Meneghel \& Oliveira, 2006).

No caso das mulheres privadas de liberdade as estratégias de resistência e visibilização no cárcere vão desde a forma com que as apenadas se maquiam e arrumam o cabelo - aspectos que lhes concedem certo arbítrio no que tange à sua apresentação pessoal e que atenuam a despersonalização e uniformização promovida pela instituição prisional (Cunha, 1994; 1996) -, até aspectos relacionados às formas de relações interpessoais estabelecidas dentro da prisão. Tais relações podem ser entendidas como a reedição de relações afetivas (filiais, maternais ou fraternais) entre as mulheres presas (Barcinski, 2012).

Versando sobre estratégias de visibilização adotadas em unidades prisionais femininas, Mariana Barcinski (2012), em pesquisa realizada com presas que se vestiam e se portavam como homens na prisão, identificou que a incorporação de trejeitos masculinos lhes garantia poder e acesso aos privilégios socialmente atribuídos aos homens, tais como o exercício legitimado da força e da poligamia. A autora enfatiza que estas apenadas eram, inclusive, reconhecidas como homens pelas colegas de encarceramento e pelo staff do presídio.

A gravidez no ambiente prisional também pode ser compreendida como um fenômeno que confere visibilidade à mulher privada de liberdade. Embora inúmeras transformações culturais tenham produzido deslocamentos em relação ao entendimento de qual seria o lugar da mulher no contexto social, a gestação representa a confirmação do estatuto de mãe, o qual ainda confere à mulher um lugar respeitável na sociedade (Brown \& Bloom, 2009; Pimentel, 2013; Ribeiro, 2007).

0 estatuto da maternidade confere à mulher presa ainda mais respeitabilidade, concedendo às grávidas e puérperas privilégios específicos no ambiente prisional. Daniela Canazaro Mello e Gabriel Gauer (2011), ao entrevistarem mulheres presas gestantes ou que estavam em companhia do filho na prisão, identificaram que estar em uma ala separada das demais galerias era visto como um privilégio por estas mulheres, principalmente porque a assistência médica, psicológica e social recebida por elas em tal ala era mais ágil e eficaz.

Álvaro Hummes Bitencourt (2012), em pesquisa realizada sobre o sentido do trabalho no cárcere, verificou que o critério estabelecido pela instituição prisional para a divisão das presas em celas superlotadas ou não estava intimamente relacionado com o envolvimento destas em atividades de trabalho. Assim, as presas vinculadas a alguma atividade laboral ficavam em celas menos povoadas, com a justificativa - por parte da direção - de que precisariam de mais horas de descanso e mais privacidade do que as demais.

De maneira geral, as celas das "trabalhadoras" - como são chamadas no sistema prisional brasileiro as celas das apenadas que desempenham alguma função laboral na prisão - são caracterizadas 
por conterem menos pessoas, por possuírem condições melhores de higiene e por terem uma menor tolerância ao uso de drogas em suas dependências. As mulheres nestas celas gozam de privilégios mais ou menos explícitos, tais como a circulação menos constrangida nos ambientes comuns da unidade prisional e um tratamento mais próximo e humanizado com os profissionais da instituição.

Considerando a argumentação aqui tecida, percebemos que há um movimento de não passividade das pessoas privadas de liberdade em meio às tentativas de uniformização que correspondem às instituições prisionais. São estes movimentos de diferenciação que permitem e promovem o processo de visibilização destas pessoas dentro da prisão, reafirmando o protagonismo e o poder de decisão pessoal em meio à rigidez das normas reguladoras.

0 que estes movimentos de resistência nos apontam são tentativas - mais ou menos deliberadas de afirmação das singularidades e de reação ao assujeitamento adoecedor do cárcere. Portanto, ao processo uniformizador engendrado pelas prisões correspondem resistências ao poder institucional da engrenagem carcerária, que promove a impotência e o "extermínio subjetivo", como nos anuncia Cristina Rauter (2007, p. 46).

\section{DA POBREZA AO CÁRCERE: UM TRAJETO (IN)EVITÁVEL?}

Para além das estratégias individuais e coletivas que visam fazer frente ao objetivo uniformizador da prisão interessa-nos, ainda, situar esta discussão em uma perspectiva mais ampla, em que se considere a vulnerabilidade da população prisional, em sua maioria oriunda de uma classe social menos favorecida, sem acesso aos serviços e às políticas socioassistenciais. É a partir desta contextualização que podemos conjeturar o improvável papel visibilizador e empoderador da prisão.

De acordo com Cristina Rauter (2007), há no contexto social atual um clamor, por grande parte da população, pela punição e pelo aprisionamento dos transgressores da ordem pública. Isto porque a criminalidade tem ganhado um lugar central na produção de subjetividade no contexto do capitalismo globalizado, o que promove a difusão de lógicas binárias que opõem os cidadãos honestos e os criminosos ou bandidos. É esta lógica do bem e do mal que perpassa os meios de comunicação e que justifica, muitas vezes, a ideia de tortura e de extermínio das pessoas em conflito com a lei.

A referida autora introduz o conceito de "dispositivo da criminalidade" (p. 42), que se constituiria como uma das principais ferramentas de controle social do mundo globalizado. Tal dispositivo incluiria o medo à criminalidade, as demandas punitivas produzidas e disseminadas pela mídia e os efeitos subjetivos que estas campanhas produzem. Nesta lógica, o estigma do criminoso seria produzido pelo próprio dispositivo da criminalidade em seus múltiplos componentes, para além do cometimento do ato criminoso (Rauter, 2007).

No Brasil, assim como em outros países, a população prisional tem aumentado vertiginosamente. 0 encarceramento em massa parece refletir uma estrutura de dominação contemporânea em que predomina o isolamento e a neutralização das pessoas provenientes de classes menos privilegiadas. Para Loïc Wacquant (1991), esta penalização - a qual denominou "ditadura sobre os pobres" (p. 6) - busca reprimir com severidade as desordens provocadas pela desregulamentação da economia, pela dessocialização do trabalho assalariado e pelo empobrecimento do proletariado urbano, aumentando a intensidade da intervenção do sistema policial e judiciário.

Em concordância com este argumento, Cecília Maria Bouças Coimbra (2006) discute o que nomeou a "criminalização da pobreza" (p. 2). A autora se baseia no dispositivo da periculosidade, introduzido por Michel Foucault e que emergiu juntamente com a sociedade disciplinar, em meados do século XIX. Segundo este dispositivo, tão importante quanto aquilo que o sujeito fez é aquilo que ele poderá vir a fazer, dependendo da sua essência. É aí que a pobreza adquire o caráter de essencialmente perigosa e criminosa e aqueles que provêm das periferias passam a representar um perigo social que deve ser erradicado, justificando o desenvolvimento de medidas coercitivas.

Sendo assim, a expansão da punição penal pode ser entendida mais como uma resposta à insegurança social ocasionada pelos altos índices de segregação racial e de classes, do que como resposta a um suposto aumento da criminalidade. Neste contexto, o superinvestimento carcerário tem sido acompanhado paralelamente por um desinvestimento social, transformando o Estado de Bem-Estar em um Estado penal (Wacquant, 2011). Nas palavras de Loïc Wacquant (1999): "a atrofia deliberada do Estado social corresponde à hipertrofia distópica do Estado penal: a miséria e a extinção de um tem como contrapartida direta e necessária, a grandeza e a prosperidade insolente do outro" (p. 51).

Segundo os dados do Conselho Nacional de Justiça (CNJ) de junho de 2014 existem atualmente mais de 560.000 pessoas privadas de liberdade no Brasil (Brasil, 2014). Destas, a maioria é negra ou parda, pobre, tem entre 18 e 29 anos e possui ensino fundamental incompleto. Em se tratando das mulheres, os dados do Ministério da Justiça de dezembro de 2012 apontam que entre 2007 e 2012 houve um crescimento de $42 \%$ na população prisional feminina, que hoje atinge o índice de mais de 35.000 
mulheres encarceradas (Brasil, 2012). A descrição desta população aponta para mulheres jovens (com média de idade 30 anos), solteiras, não brancas, com baixa escolaridade e com histórico de ruptura de vínculos familiares. Dentre o crime mais cometido por elas está o envolvimento com o tráfico de drogas (Carvalho et al., 2006; Cerneka, 2009; Shamai \& Kochal, 2008).

De maneira geral, a realidade social das pessoas que estão privadas de liberdade é atravessada por um histórico de educação deficitária, infração juvenil, uso de drogas e envolvimento com o tráfico. No que se refere às mulheres, sobressaem as histórias prévias de violência, de abandono e de cooptação por homens criminosos (Carvalho et al., 2006; Huang, Atlas \& Parvez, 2012). Para Heidi Ann Cerneka (2009), a pobreza e a dependência química são os fatores mais associados ao engajamento das mulheres em atividades criminosas. Nesse sentido, o encarceramento, de modo geral, exclui aqueles que já se encontram socialmente excluídos (Carlen, 2007; Carvalho et al., 2006).

É a partir de uma análise da população carcerária, especialmente das múltiplas violências e privações historicamente experimentadas por ela, que apontamos o paradoxo operado pelo sistema prisional. Excluídas de um sistema social que não as reconhece como sujeito de direitos em suas necessidades básicas de proteção social, saúde e trabalho, as pessoas privadas de liberdade podem encontrar justamente na prisão a possibilidade de acessar a determinados serviços (Huang, Atlas \& Parvez, 2012). Portanto, é através do acesso facilitado a direitos e serviços que a população carcerária subverte o processo invisibilizador promovido pela prisão. Ironicamente, o mesmo Estado que historicamente exclui é aquele que, ao possibilitar este acesso, permite que esta população se torne visível, ainda que circunscrita ao ambiente prisional.

No ano de 2014 foi implementada no Brasil a Política Nacional de Atenção Integral à Saúde das Pessoas Privadas de Liberdade no Sistema Prisional(PNAISP). De acordo com a Política, cada complexo penitenciário e/ou unidade prisional deve ser composto por uma equipe de atenção básica multidisciplinar que contenha cirurgião dentista, enfermeiro, médico, técnico de enfermagem e técnico de higiene bucal. Em unidades que abarquem um contingente populacional maior, tais equipes podem ser acrescidas de outros profissionais, como médico psiquiatra, assistente social, farmacêutico, fisioterapeuta, psicólogo, terapeuta ocupacional e nutricionista. Além da composição da equipe, a PNAISP prevê que os serviços de saúde dentro das instituições prisionais estejam integrados a uma Unidade Básica de Saúde fora das instituições (Brasil, 2014a). É a partir da implementação desta política que podemos conjeturar que, para muitas pessoas, é justamente pela via do cárcere que o acesso à saúde poderá se materializar.

Para além do acesso à saúde, em muitas situações, o encarceramento é percebido como um fator de proteção e como uma forma de interrupção temporária de situações de abuso continuado, uma vez que muitas mulheres, por exemplo, viviam em situações de grandes privações econômicas e sociais no momento anterior à prisão (Matos \& Machado, 2007; Mello \& Gauer, 2011). Assim, a vida na prisão pode ser vivenciada como um ambiente seguro comparado com o ambiente inseguro em que algumas mulheres viviam. A respeito disto, e igualmente sobre a situação de mulheres encarceradas, Michal Shamai e RinatBilly Kochal (2008) sugerem que não raramente a instituição prisão atua para elas como uma "figura parental positiva" (p. 337) que supre suas necessidades físicas básicas, tais como uma rotina diária que inclui comida e um lugar para dormir.

Diante das argumentações aqui tecidas, entendemos que a fragilidade das redes extramuros, o acesso limitado aos direitos sociais e a submissão a múltiplas violências pode fazer com que a instituição prisional tenha um efeito empoderador nas pessoas privadas de liberdade. Assim, a prisão - ao contrário do que se poderia supor - pode proporcionar um espaço alternativo de desenvolvimento da individualidade e singularidade para os indivíduos em contexto de encarceramento. Em outras palavras, a prisão opera simultaneamente processos de apagamentos subjetivos, de visibilização pessoal e de afirmação de potencialidades.

\section{CONSIDERAÇÕES FINAIS}

As reflexões aqui apresentadas não pretendem se configurar em uma apologia ao encarceramento ou apontar para uma suposta eficácia do sistema prisional na provisão de benefícios aos seus internos. 0 que pretendemos é elucidar os diversos atravessamentos implicados no processo de encarceramento, bem como as contradições dele resultantes. Conforme exposto ao longo do trabalho, os movimentos de não passividade e de visibilidade adotados pelas pessoas privadas de liberdade são, na verdade, reações que visam minimizar os efeitos devastadores de um sistema prisional que, via de regra, corrói e aniquila o eu dos sujeitos que nele habitam.

Segundo Frédéric Gros (2002), podemos identificar a coexistência de uma variedade de discursos utilizados pela sociedade para justificar a pena privativa de liberdade. Dentre eles, o autor destaca o discurso moral e sagrado que afirma que "punir é recordar a lei"; o discurso político-econômico que se 
sustenta pelos interesses de uma comunidade que se diz ameaçada, no sentido de que "punir é defender a sociedade"; bem como o discurso psicopedagógico que se baseia na ideia de que "punir é educar o indivíduo" (Gros, 2002, p. 12-13).

Contrariamente a estes e a outros discursos populares que nos falam sobre uma possível infalibilidade do sistema prisional e que sustenta a posição de que as pessoas em situação de prisão devem trabalhar para pagar pelas supostas benesses do cárcere (comida, abrigo, saúde, etc), não entendemos que esta população seja beneficiada socialmente. Na realidade, compreendemos que assumir que a prisão pode se constituir como um espaço de proteção, de visibilização e desenvolvimento de potencialidades, é apontar para a precariedade de um Estado que se vê incapaz de prover os direitos básicos constitucionalmente estabelecidos, possibilitando que uma cultura marginal (e que floresce em ambiente segregado) seja capaz de produzir efeitos mais positivos do que os suscitados pela vida fora das grades.

\section{Referências}

Barcinski, M. (2012). Expressões da homossexualidade feminina no encarceramento: o significado de se "transformar em homem" na prisão. Psico-USF, 17(3), 437-446.

Bitencourt, A. H. (2012). Mulheres e sistema prisional: o sentido do trabalho para quem viveu e vive sob a égide do cárcere. Dissertação (Mestrado em Ciências Sociais). Pontifícia Universidade Católica do Rio Grande do Sul, Porto Alegre, 2012.

Brasil. (2012). Ministério da Justiça. Departamento Penitenciário Nacional. Infopen Estatística. Disponível em: http://www.mj.gov.br/depen. Acesso em: 17 junho 2014.

Brasil. (2014). Conselho Nacional de Justiça. Novo diagnóstico de pessoas presas no Brasil. Disponível em: http://www.cnj.jus.br/images/imprensa/diagnostico_de_pessoas_presas_correcao.pdf. Acesso em: 20 junho 2014.

Brasil. (2014a). Ministério da Saúde e Ministério da Justiça. Política Nacional de Atenção Integral à Saúde das Pessoas Privadas de Liberdade no Sistema Prisional. Disponível em: http://www.conass.org.br/Notas\%20t\%C3\%A9cnicas\%202013/NT\%2033-

\%202013\%20Poli\%CC\%81tica\%20Sau\%CC\%81de\%20Prisional.pdf. Acesso em: 15 junho 2014.

Brown, M., \& Bloom, B. (2009). Reentry and Renegotiating Motherhood: Maternal Identity and Success on Parole. Crime \& Delinquency, 55(2), 313-336.

Carlen, P. (2007). A reclusão de mulheres e a indústria de reintegração. Análise Social, 52(185), 10051019.

Carvalho, M. L., Valente, J. G., Assis, S. G., \& Vasconcelos, A. G. G. (2006). Perfil dos internos no sistema prisional do Rio de Janeiro: especificidades de gênero no processo de exclusão social. Ciência \& Saúde Coletiva, 11(2), 461-471.

Cerneka, H. A. (2009). Homens que menstruam: considerações acerca do sistema prisional às especificidades da mulher. Veredas do Direito, 6(11), 61-78.

Coimbra, C. (2006). Direitos Humanos e Criminalização da Pobreza. Trabalho apresentado em Mesa Redonda: Direitos Humanos e Criminalização da Pobreza no I Seminário Internacional de Direitos Humanos, Violência e Pobreza: a situação de crianças e adolescentes na América Latina hoje, Rio de Janeiro, RJ, Brasil.

Colares, L. B. C., \& Chies, L. A. B. (2010). Mulheres nas so(m)bras: invisibilidade, reciclagem e dominação viril em presídios masculinamente mistos. Revista Estudos Feministas, 18(2), 407-423.

Cunha, M. I. P. (1991). A prisão feminina como 'ilha de Lesbos' e 'escola do crime': discursos, representações, práticas. In Medeiros, C. L. (Org.). Do desvio à instituição total: subcultura, estigma, trajectos (pp. 163-184). Lisboa: Centro de Estudos Judiciários.

Cunha, M. I. P. (1994), Malhas que a reclusão tece. Questões de identidade numa prisão feminina. Lisboa: Gabinete de Estudos Jurídico-Sociais.

Cunha, M. P. (1996). 0 corpo recluído: controlo e resistência numa prisão feminina. In Almeida, M. V. de (Org.). "Corpo presente: treze reflexões antropológicas sobre o corpo" (pp. 1-23). Oeiras: Celta.

Cunha, M. I. P. (2007). A reclusão segundo o gênero: os estudos prisionais, a reclusão de mulheres e a variação dos contextos da identidade. In AAVV, Educar o Outro: As Questões de Género, dos Direitos Humanos e da Educação nas Prisões Portuguesas (pp. 80-89). Coimbra: Publicações Humanas.

Fonseca, K. P. (2006). Re(pensando) o crime como uma relação de antagonismo entre seus autores e a sociedade. Psicologia: ciência e profissão, 26(4), 532-547.

Forsyth, C. J. (2003). Pondering the discourse of prison mamas: a research note. Deviant Behavior: An Interdisciplinary Journal, 24(3), 269-280.

Foucault, M. (1987). Vigiar e Punir: Nascimento da prisão. Petrópolis, RJ: Vozes. (Original publicado em 1975). 
Goffman, E. (1996). Manicômios, prisões e conventos. (D. M. Leite. Trad.). Editora Perspectiva.

Gros, F. (2002). Os quatro sentidos da pena. In: Garapon, A., Gros, F., \& Pech, T. (Orgs.). Punir em democracia. E a justiça será. São Paulo: Instituto Piaget.

Guimarães, C. F., Meneghel, S. N., \& Oliveira, C. S. (2006). Subjetividade e estratégias de resistência na prisão. Psicologia: Ciência e Profissão, 26(4), 632-645.

Huang, K., Atlas, R., \& Parvez, F. (2012). The Significance of Breastfeeding to Incarcerated Pregnant Women: An Exploratory Study. Birth, 39(2), 145-155.

Matos, R., \& Machado, C. (2007). Reclusão e laços sociais: discursos no feminino. Análise Social, 40(185), 1041-1054.

Mello, D. C., \& Gauer, G. (2011). Vivências da maternidade em uma prisão feminina do estado rio grande do sul. Saúde e Transformação Social, 1(3), 113-121.

Miyamoto, Y., \& Krohling, A. (2012). Sistema prisional brasileiro sob a perspectiva de gênero: invisibilidade e desigualdade social da mulher encarcerada. Direito, Estado e Sociedade, 40, 223241.

Moe, A. M., \& Ferraro, K. J. (2006). Criminalized mothers: the value and devaluation of parenthood from behind bars. Women \& Therapy, 29(3-4), 135-164.

Pimentel, E. (2013). 0 lado oculto das prisões femininas: representações dos sentimentos em torno do crime e da pena. Latitude, 7(2), 51-68.

Rauter, C. (2007). Clínica e estratégias de resistência: perspectivas para o trabalho do psicólogo em prisões. Psicologia \& Sociedade, 19(2), 42-47.

Resende, S.H. (2013). Narrativas de presos condenados: um vocabulário da prisão. Revista Eletrônica de Educação, 7(1), 361-368.

Ribeiro, F. B. (2007). Maternidades à margem: gravidez e nascimento numa instituição de proteção à infância. História: Questões \& Debates, 47, 139-155.

Shamai, M., \& Kochal, R. B. (2008). "Motherhood starts in prison": the experience of motherhood among women in prison. Family process, 47(3), 323-340.

Silva, M. F., \& Guzzo, R. S. L. (2007). Presidiários: percepções e sentimentos acerca de sua condição paterna. Revista Brasileira de Crescimento e Desenvolvimento Humano, 17(3), 48-59.

Wacquant, L. (1999). As prisões da miséria (A. Telles, Trad.). Rio de Janeiro: Zahar.

Wacquant, L. (2011). A política punitiva da marginalidade: revisitando a fusão entre Workfare e Prisonfare (J. Alexim, Trad.). Social Justice, 38(1-2), 203-221.

Historial do artigo

Recebido $\quad 31 / 07 / 2014$

Aceite $\quad 25 / 11 / 2014$

Publicado $\quad 12 / 2014$ 